\title{
EFEITO DAS GEADAS EM CULTURAS ENERGÉTICAS ${ }^{1}$
}

Samara Moreira Perissato ${ }^{2}$, Wesler Luiz Marcelino ${ }^{3}$, Laura Feuser $\mathrm{Acco}^{4}$, Ana Claudia Cabral ${ }^{5}$, Luana Patricia Pinto $^{6}$, Jianice Pires Frigo ${ }^{7}$

\footnotetext{
${ }^{1}$ Aceito para publicação no $4^{\circ}$ trimestre de 2013

${ }^{2}$ Acadêmica em Agronomia pela Universidade Federal do Paraná - Campus Palotina, Brasil.

${ }^{3}$ Acadêmico em Agronomia pela Universidade Federal do Paraná - Campus Palotina, Brasil.

${ }^{4}$ Acadêmica em Agronomia pela Universidade Federal do Paraná - Campus Palotina, Brasil.

${ }^{5}$ Engenheira Ambiental, Mestranda em Energia na Agricultura pela Universidade Estadual do Oeste do Paraná, Cascavel/PR, Brasil.

${ }^{6}$ Acadêmica em Ciências Biológicas pela Universidade Federal do Paraná - Campus Palotina, Brasil.

${ }^{7}$ Acadêmica em Agronomia pela Universidade Regional Integral do Alto Uruguai e das Missões - URI campos de Santiago, Brasil.
}

\section{Resumo}

O conhecimento dos efeitos de fenômenos climáticos extremos, como as geadas em diversas culturas é de grande importância para o zoneamento climático visando à otimização dos resultados de produção. As fontes de energias alternativas e a utilização de biodiesel vêm abrindo um mercado promissor para as culturas energéticas como Pinhão manso, Girassol, Eucalipto e outras, portanto se faz necessário estabelecer relações entre as culturas e os efeitos fisiológicos que as geadas podem causar a estas. Deste modo, o presente trabalho objetiva trazer informações técnico-científicas sobre o assunto, levando em consideração a falta de estudos nesta área.

Palavras chave: zoneamento climático, biocombustível, efeitos fisiológicos.

\section{EFFECT OF FROST ON ENERGY CROPS}

\begin{abstract}
Knowledge of the effects of extreme weather events such as frosts across cultures is of great importance for the climatic zoning aiming the optimization of production results. Alternative sources of energy and the use of biodiesel has opened a promising market for energy crops like jatropha, sunflower, eucalyptus and other therefore it is necessary to establish relationships
\end{abstract}


between cultures and the physiological effects that can cause these frosts. Thus, this work aims to bring technical and scientific information on the subject, taking into account the lack of studies in this área.

Keywords: climatic zoning, biofuel, physiological effects.

\section{Introdução}

Fenômenos extremos como as geadas, podem afetar de maneira negativa a agricultura, causando danos fisiológicos às plantas, levando a queda de produção e prejuízos ao agricultor (AGUIAR et al., 2004). Assim, seu conhecimento e distribuição espacial se faz necessário para definição de regiões potenciais e para a implantação de uma cultura resistente (OLIVEIRA et al., 2012).

É crescente o uso de energia alternativa a partir da produção dos biocombustíveis, visando reduzir a dependência das importações de petróleo e mitigar os efeitos deletérios do aquecimento global, assim o uso de culturas agroenergéticas tem ganhado destaque na produção agrícola brasileira (BILICH; DASILVA, 2006; TOSCANO et al., 2010).

Poucos estudos mostram os danos que as geadas causam nas culturas enérgicas, em alguns casos, como mostra Ximenes et al., (2004) sabe-se que a massa acumulada pelos grãos pode diminuir, tanto quanto reduzir a área foliar ativa fisiologicamente em milho danificado por geadas.

Tendo em vista a necessidade de conhecer sobre os efeitos que as geadas causam sobre as culturas energéticas, a revisão de literatura tem por objetivo relacionar estes fatores climatológicos extremos a produção destas culturas.

\section{Geada e seus efeitos sobre os vegetais}

As geadas são fenômenos climáticos que podem provocam congelamento nos tecidos vegetais, provocando a morte das plantas ou de suas partes. Esse processo resulta na perda do potencial de turgescência, redução do volume celular e resulta na desidratação das células. Como sintomas desses processos, a folha fica com coloração verde escura e flácida, passando a ficar seca com o tempo. No caule, os vasos ficam necrosados (escuros) e provoca danos generalizados interna e externamente nos frutos (SENTELHAS et al, 2012).

Quando a geada se deposita na planta ocasiona o congelamento do protoplasma das células, destruindo o tecido vegetal e, possivelmente, matando a mesma. Existem temperaturas de agressões diferentes dependendo de cada espécie vegetal, em alguns casos a planta pode 
continuar viva mesmo com a ocorrência destes fenômenos. Para cada espécie vegetal há uma temperatura em que o congelamento do protoplasma ocorrerá, sendo possível que ocorra antes da temperatura chegar a zero grau. Outras espécies podem apresentar uma maior resistência ao congelamento, continuando vivas mesmo após o fenômeno ter ocorrido (BISCARO, 2007).

Existem dois tipos principais de geadas quanto a sua formação: advecção ou de vento frio e geada de radiação. A primeira é provocada pelas ocorrências de fortes ventos e massas de ar constantes e de temperaturas mínimas. O vento, deste modo, resseca a parte da planta em contato e pode levar a morte do tecido vegetal daquele determinado local (SENTELHAS et al, 2012). Já a geada de radiação acontece em noites calmas e claras, devido ao rápido resfriamento da camada de ar próxima ao solo, oriundo das grandes perdas de radiação terrestre (AYOADE, 2011).

Segundo Sentelhas et al., (2012) as geadas ainda podem ser subdivididas em dois aspectos visuais: Branca e Negra. A geada branca ocorre quando a umidade do ar se condensa em contato com o orvalho, com as baixas temperaturas e se deposita na planta, formando um aspecto de cristais. Já a segunda, ocorre quando o ponto de orvalho é muito baixo e a temperatura negativa atinge as plantas sem que o orvalho se condense, fazendo com que a planta apresente um aspecto necrótico (MELO-ABREU et al., 2010)

As regiões temperadas e as áreas subtropicais estão sujeitas a ocorrência de geadas, já nos trópicos, são raras, com exceção das montanhas isoladas (AYOADE, 2011). O Brasil, por possuir grande área territorial, também apresenta uma considerável heterogeneidade climática, tipos de solo e topografia, no país as geadas são frequentes nas latitudes acima do paralelo $19^{\circ} \mathrm{S}$, atingindo os estados de São Paulo, Mato Grosso do Sul, Minas Gerais, Paraná, Santa Catarina e Rio Grande do Sul, podendo causar danos e perdas relevantes nessas áreas (PEREIRA et al., 2001).

Assad et al., (2004) levou em consideração os prognósticos das mudanças climáticas e o efeito estufa no Brasil, admitindo que em algum tempo as regiões de baixas temperaturas, que atualmente são limitantes ao desenvolvimento de culturas suscetíveis a geada, com o aumento do nível térmico, passarão a apresentar crescimento favorável de várias culturas (ASSAD et al., 2004).

Melo-Abreu (2010) afirma que as plantas possuem mecanismo de defesa, e algumas desenvolveram um mecanismo de tolerância á congelação. Uma única planta tem resistência diferenciada de acordo com seu estado de desenvolvimento, concentração de nucleadores de gelo nas suas superfícies e grau de aclimação. Algumas bactérias são ativas na nucleação do gelo, e ocorrem em concentrações variáveis de acordo com as operações culturais realizadas, 
microclima e tipo de cobertura do solo. Uma elevada concentração dessas bactérias pode elevar a temperatura de congelação em alguns graus Celsius.

Em temperaturas abaixo de $0^{\circ} \mathrm{C}$, as células são afetadas metabolicamente, diminuindo ao mínimo as funções fisiológicas mais importantes. A prevenção se dá através de processos que evitam a formação de gelo, quer pela proteção de partes ou órgãos das plantas contra baixas temperaturas, quer pela síntese de solutos que aumentam a concentração osmótica intracelular ou pela diminuição do ponto de fusão da água, dificultando a saída da água para formação do gelo extracelular. Os mecanismos de prevenção são estratégias adequadas de plantas em regiões onde ocorrem geadas leves, durante o período de crescimento e atividade metabólica (HIGA et al., 2000).

O espaçamento entre as plantas é um dos fatores que pode estar relacionado com os danos provocados por geada, isso em razão da radiação solar interceptada através do dossel formado. $\mathrm{Na}$ linha de plantio, nos espaçamentos menores, ou seja, com maior densidade de plantas, ocorre formação de dossel precocemente quando comparado com os espaçamentos maiores (PILAU et al., 2007).

O tipo de cultura também pode influenciar nos efeitos das geadas levando em consideração suas distinções fisiológicas e morfológicas, assim como suas necessidades climáticas individuais. Seu comportamento é limitado na maioria das vezes pelo período em que é submetida ao dano, podendo a queima de tecidos da planta, por exemplo, estar relacionada a fatores anatômicos, fisiológicos e genéticos (SILVA et al., 2008).

\section{Culturas energéticas}

Culturas energéticas ou bioenergéticas originam a biomassa e esta é uma fonte de energia renovável, a qual pode ser convertida em combustíveis gasosos, líquidos ou sólidos, gerando calor para aquecimento, eletricidade ou combustíveis. (CHECHETO et al., 2010). No Brasil, as principais matérias primas para a produção de biodiesel são: soja, milho, girassol, amendoim, algodão, canola, mamona, babaçu, palma (dendê) e macaúba, entre outras oleaginosas, além da grande utilização de óleos residuais e gordura animal (ALVES, 2010).

O aproveitamento dos recursos naturais como fonte de energia, pode ser a chave de muitos problemas, uma vez que reduzindo o consumo de energias fósseis e não renováveis ocorre à diminuição das emissões de gases de efeito estufa. Outra vantagem esta em relação com as fontes de energia convencionais, onde os custos são mais baixos, havendo uma menor dependência em relação a variações climáticas de curto prazo e a promoção de estruturas 
regionais, tudo isso tirando o fato de construir uma fonte de rendimento para os agricultores (PINTO et al., 2013).

Como desvantagem associada à produção de culturas energéticas, está à intensidade do uso de área agrícola, além disso, com a utilização de culturas alimentares como canola, milho e soja, pode acorrer o aumento do preço dos alimentos (ANTUNES et al., 2010).

O pinhão manso (Jatrhpha cuscas L.) é apontado como uma cultura energética de grande potência, tendo em vista que o volume do óleo produzido em média é de 33 a 38\% pela planta dependendo da associação das características produtivas e vegetativas em um determinado ambiente (SOUSA, 2012).

Levando em consideração aspectos agronômicos, como teor de óleo, produtividade, sistema produtivo, ciclo de cultura, etc., acredita-se que o Crambe seja outra importante cultura para a produção de biodisel. Seu cultivo iniciou-se no Brasil no ano de 1995, com intuito de rotação de cultura, mas hoje é cultivada em maior escala no México e Estados Unidos para a produção de óleo industrial (JASPER et al., 2010). Este óleo apresenta características importantes como teor de ácido erúcico (cerca de 55 \%) que lhe proporciona alta estabilidade a oxidação (PITOL, 2008).

Outra cultura que se destaca é a mamona - Ricinus communis L. que além do interesse industrial, pelo seu óleo, também vem sendo utilizada na composição de inúmeros produtos como tintas, vernizes, cosméticos, lubrificantes, plásticos, etc. As características químicas do seu óleo é quase exclusivamente de um único ácido graxo (ácido ricinoléico) que contém uma hidroxila que lhe torna solúvel em álcool a baixa temperatura. No Brasil a cultura da mamona vem conquistando cada vez mais seu espaço, principalmente nos estados do Nordeste e Centro Oeste devido ao interesse pela indústria ricinoquímica e pela busca de fontes energéticas (RIZZI et al., 2010).

O cultivo de plantas lenhosas também é relacionado à obtenção de biomassa para fins energéticos como, por exemplo, o Eucalyptus globulus, devido à capacidade de produção de calor e energia elétrica a partir de sua combustão. Contudo, este tipo de biomassa requer um pré-tratamento que permita a sua adequada limpeza, com os custos implícitos deste processo (GONÇALVES, 2010).

Uma cultura que também ganha espaço no Brasil é o girassol, pois apresenta pouca sensibilidade às variações no fotoperíodo. O óleo obtido das sementes de girassol apresenta mais de $80 \%$ dos seus ácidos graxos insaturados, linoleico, na maior parte (GAZZOLA et al., 2008). 
A canola (Brassica napus L. var oleífera), por sua vez é uma espécie oleaginosa, da família das crucíferas, passível de incorporação nos sistemas de produção de grãos do Sul do Brasil. Destaca-se como uma excelente alternativa econômica. Seu cultivo requer estações frescas, úmidas e temperaturas frias á noite (TOMM, 2007).

\section{Influência das geadas em algumas culturas energéticas}

Com o aumento de produção e demanda das culturas energéticas se faz necessário relacionar algumas delas com efeitos climáticos, objetivando o zoneamento climático. $\mathrm{O}$ promissor Pinhão Manso (Jatrhpha cuscas L) além de ter seu alto rendimento na produção de óleo, é pouco exigente climaticamente. Assim, esta cultura possui grande adaptabilidade nas mais diversas regiões, o que intensifica seu uso. Geadas fortes são prejudiciais para a cultura, entretanto, elas são tolerantes a geadas de pouca intensidade. Apesar disto, com sua ocorrência, podem acabar perdendo boa parte de suas folhas, o que consequentemente reduzirá sua produção (SATURNINO et al., 2005).

Após o experimento, Andrade et al. (2008), concluiu que a temperatura mínima crítica para o cultivo do pinhão manso, sendo estas plantas jovens, se estabelece entre -3 e $-4{ }^{\circ} \mathrm{C}$, em condições de ambiente controlado. Seguindo esta metodologia, as plantas adquirem uma grande capacidade de recuperação de danos causados em temperaturas acima de $-3{ }^{\circ} \mathrm{C}$.

Sobre a cultura do Crambe, segundo Toebe et al. (2010) esta é tolerante ao frio sendo que a planta é capaz de resistir sem maiores danos a temperaturas de até $-6,0^{\circ} \mathrm{C}$ e requer temperaturas entre $15^{\circ} \mathrm{C} \mathrm{e} 25^{\circ} \mathrm{C}$ em seu período vegetativo (FALASCA et al., 2010). O Crambre também apresenta tolerância à seca, segundo Pitol et al., (2008) porém é sensível a geadas fortes na fase de plântula e no florescimento. Para atingir sua maturação fisiológica, necessita de 1.350 graus-dia (considerando temperatura mínima de $2,5^{\circ} \mathrm{C}$ ) durante todo seu ciclo. Durante a germinação e estabelecimento da lavoura requer boa umidade e após o florescimento, a seca é ideal para seu desenvolvimento e baixa incidência de doenças.

Já a mamoneira é uma planta de clima tropical e subtropical, de ampla capacidade de adaptação. Precisa de chuvas regulares principalmente no início da fase vegetativa e de período seco na maturação dos frutos. Mesmo com elevada capacidade de adaptação à mamoneira não tolera geadas durante o seu ciclo de desenvolvimento. O risco de geadas deve ser considerado um fator restritivo ao cultivo desta espécie (BELTRÃO et al., 2008).

A utilização de culturas energéticas de floresta, também se faz bastante intensiva, sendo o Eucalipto (Eucalyptus) uma das mais utilizadas (GONÇALVES, 2010). Em estudos de HIGA et al. (2000) avaliando os danos causados por geadas em progênies de Eucalyptus dunnii 
Maiden no Estado do Paraná, observaram que após um mês da ocorrência de geada, todas as plantas mostravam danos visíveis, apresentando ainda, plantas totalmente queimadas em uma porcentagem de 4,76. Contudo, considerando os efeitos nove meses após a ocorrência da geadas, 3,87\% das plantas não apresentavam nenhum sinal de dano. Paludzyszyn Filho e Santos (2005) afirmam que temperaturas abaixo ou próximas a $0{ }^{\circ} \mathrm{C}$, resultam em dados, desde a perda da área foliar até a morte das plantas de eucalipto.

Já resultados de estudos de Souza et al. (2011), mostraram que o eucalipto, em comparação com outras árvores utilizadas no sistema agroflorestal como angico-vermelho (Parapiptadenia rigida), bracatinga (Mimosa scabrella) mostram-se muito resistentes, enquanto a canafístula (Peltophorum dubium) demonstrou ser apenas resistente.

A cultura agroenergética de girassol é considerada muito sensível à geada na emergência e durante a floração, o que no último caso pode levar a infertilidade total das flores que se abriram no dia de baixa temperatura. Temperaturas próximas a $0^{\circ} \mathrm{C}$ não matam a planta, mas podem causar distúrbios fisiológicos como a formação de plantas multicapituladas devido à queima da gema apical. Esse problema é comum em plantios safrinha em regiões sujeitas a geadas (GAZZOLA et al., 2012).

A canola é considerada uma espécie oleaginosa de clima frio. No início do desenvolvimento da planta a geada prejudica o florescimento e o enchimento de grãos. Nessa fase a geada pode causar retenção de clorofila nos grãos e abortamento de flores, formando grãos verdes, que afetam negativamente a qualidade e a produção de grãos. Assim, a cultura deve passar por um período de aclimatação ao frio para resistir às geadas, processo que induz mudanças fisiológicas, bioquímicas, morfológicas, e moleculares que tornam as plantas resistentes não somente a temperaturas congelantes, mas especialmente à desidratação provocada pelo congelamento (DALMAGO et al., 2010).

\section{Considerações Finais}

Com a crescente demanda de biocombustíveis, as culturas energéticas ganham destaque na produção brasileira. Assim, entender os mecanismos fisiológicos em relação aos efeitos das geadas auxiliam na elaboração de um planejamento agrícola. Como exemplificadas na literatura, o Pinhão Manso, Crambe, Mamona, Eucalipto, Girassol e Canola apresentam-se resistentes em específicas fases de desenvolvimento de cada cultura e, normalmente, em geadas de baixa intensidade, já quando o fenômeno climático é intenso, podem ocorrer distúrbios fisiológicos ou até a morte da planta. 


\section{Referências}

AGUIAR, D.; MENDONÇA, M. Climatologia das geadas em Santa Catarina. In: Simpósio Brasileiro de Desastres Naturais. Anais. Florianópolis, 2004.

ALVES, O. F. Análise sócio - econômica da implantação de uma usina de biodiesel no Estado do Maranhão. Dissertação - Instituto de Tecnologia para o Desenvolvimento -LACTEC. Curitiba, 2010.

ANDRADE, G. A. et al. Temperatura mínima letal para plantas jovens de Pinhão-Manso. Agrometeorologia, V.67, p.799-803, 2008.

ANTUNES, R.; SILVA, I.C.; Utilização de algas para a produção de biocombustíveis; Instituto Nacional da Propriedade Industrial - Dezembro 2010.

ASSAD, E. D. et al., Impacto das mudanças climáticas no zoneamento agroclimático do café no Brasil. Pesq. agropecuária brasileira, Brasília, v.39, n.11, p.1057-1064, nov. 2004.

AYOADE, J. O. Introdução à climatologia para os trópicos, $15^{\mathrm{a}}$ Edição, Rio de Janeiro: Bertrand, 2011.

BELTÃO, N.E.M. et al. Enfoque Agrometeorológico para Cultura da Mamoneira. Campina Grande, PB Junho, 2008.

BILICH, F.; DASILVA, R. Análise multicritério da produção de biodiesel. XIII Simpósio de Engenharia de Produção. Anais... Bauru, SP, Brasil: [s.n.]., 2006.

BÍSCARO, G. A. Meteorologia agrícola básica. UNIGRAF, Gráfica e Editora União Ltda. 2007.

CHECHETO, R. G.; Siqueira, R.; GAMERO, C. A.; Balanço energético para a produção de biodiesel pela cultura da mamona (Ricinus communis L.); Revista Ciência Agronomica. vol. 41 no. 4 ; Fortaleza - Nov./Dec. 2010.

DALMAGO, G.A. et al. Aclimatação ao frio e dano por geada em canola, Pesq. agropec. bras. vol.45 no.9 Brasília Sept. 2010.

FALASCA, S. L.; LAMAS, M. C.; CARBALLO, S. M.; ANSCHAU, A. Crambe abyssinica: An almost unknown crop with a promissory future to produce biodiesel in Argentina. International Journal of Hydrogen Energy, v.35, p.5808-5812, 2010.

GAZZOLA, A. et al. A cultura do girassol. Piracicaba - SP. Junho de 2012

GONÇALVES, M. M. S. Análise ambiental e energética da produção de Eucalyptus globulus para a conversão em energia elétrica. Dissertação em Engenharia do Ambiente. 2010.

HIGA, R. C. V. et al. Resistencia e resiliência a geadas em Eucalyptus dunnii MAIDEN, plantados em campo do tenente, PR. Bol. Pesq. Fl., Colombo, n. 40, 2000. 
JASPER, S. P.; BIAGGIONI, M. A. M.; Silva, P. R. A.; Seki, A. S.; Bueno, O. C.; Análise Energética da cultura do crambe (Crambe abyssinica hochst) produzida em plantio direto; Engenharia Agrícola; vol.30 no.3; Jaboticabal - Junho 2010.

MELO-ABREU, J. P.; RIBEIRO, A. C. Os danos de geada: conceitos, mecanismos e modelos de simulação. Workshop Clima e Recursos Naturais 2010.

OLIVEIRA, R. P.; JOÃO, P. L. et al. Manejo de Pomares de Citrus contra Geadas. Embrapa clima temperado. Pelotas, 2012.

PALUDZYSZYN FILHO, E.; SANTOS, P.E.T. Considerações sobre o plantio de Eucalyptus dunnii, no estado do Paraná. Colombo: EMBRAPA, 2005. 7p. (Comunicado Técnico, 141).

PEREIRA, A. R.; ANGELOCCI, L. R., SENTELHAS, P. C. Agrometeorologia: fundamentos e aplicações práticas. Guaíba: Agropecuária, 2001. 478p.

PILAU, F.G. et al. Radiation balance of an orange tree in orchard and its relation with global solar radiation and grass net radiation. Revista Brasileira de Agrometeorologia, Piracicaba, v.15, n.3, p.257-266, 2007.

PINTO, T.; Lousada, J.; LOURO, G.; MACHADO, H.; NUNES, L.; Recolha de Biomassa Florestal: Avaliação dos Custos e Tempos de Trabalho; Silva Lusitana; vol.21 no.Especial Lisboa - Junho 2013

PITOL, C. Cultura do Crambe. Tecnologia e Produção: Milho Safrinha e Culturas de Inverno. Maracaju: Fundação MS, 2008.

RIZZI, B. et al., Mamona como biocombustível. Revista de divulgação do Projeto Universidade Petrobras e IF Fluminense v. 1, p. 317-320, 2010.

SATURNINO, H. M. et al. Cultura do pinhão-manso (Jatropha curcas L.). In: Produção de oleaginosas para biodiesel. Informe Agropecuário, v. 26, n. 229, p. 44-78, 2005.

SENTELHAS, P.C.; ANGELOCCI, L.R. Entendendo a Geada, 2012. Disponível em <http://www.climaonline.com.br/artigo03.php.> Acesso em: 30 nov. 2013.

SILVA, E. P., CUNHA, G. R., PIRES, J. L. F., et al. Fatores abióticos envolvidos na tolerância de trigo à geada. Pesquisa Agropecuária brasileira. V.43, Brasília, 2008.

SOUSA, A. E. C.; GHEYI, H. R.; Soares, F. A. L.; Nobre, R. G.; Nascimento, E. C. S.; Componentes de produção de pinhão manso irrigado com água de diferentes condutividades elétrica e doses de fósforo; Ciência Rural; vol.42 no.6; Santa Maria - Junho 2012.

SOUZA. V. Q. et al. Resistência de espécies arbóreas submetidas a extremos climáticos de geada em diferentes sistemas agroflorestais. Ciência Rural, Santa Maria, 2011.

TOEBE, M.; BRUM, B.; LOPES, S. J.; et al. Estimativa da área foliar de Crambe abyssinica por discos foliares e por fotos digitais. Ciência Rural, Santa Maria, v.40, n.2, p.475-478. 2010. 
TOMM, G. O. Indicativos tecnológicos para produção de canola no Rio Grande do Sul. Ministério da Agricultura, Pecuária e Abastacimento. Passo Fundo, 2007.

TOSCANO, E. M.; COSTA, A. S.; AMORIM, A.; SILVA, G. M. C. Biodiesel: uma utilização da biotecnologia a favor do desenvolvimento socioeconômico e ambiental no Brasil. IV Congresso Brasileiro de Mamona e I Simpósio Internacional de Oleaginosas Energéticas. Anais... João Pessoa, PB: [s.n.]. , 2010.

XIMENES, A. C. A.; SOUZA, L. C. F.; ROBAINA, A. D.; GONÇALVES, M. C. Avaliação da incidência de Geadas em componentes de Produtividade do Milho. Revista Brasileira de Milho e Sorgo, v3. 2004. 